\title{
Prostatic Melanosis: Case Report
}

\author{
Gizem Teoman (D), İsmail Saygın (D), Sevdegül Mungan (1) \\ Department of Pathology, Karadeniz Technical University School of Medicine, Trabzon, Turkey \\ Cite this article as: Teoman G, Saygın I, Mungan S. Prostatic Melanosis: A Case Report. JAREM 2019; 9(1): 58-60.
}

\begin{abstract}
Prostatic melanosis is a rare lesion characterized by melanocytic proliferation in the prostatic epithelium and stroma. This entity is absolutely benign and it is not a precursor for malignant melanoma. Yet, the pathogenesis of prostatic melanosis is not fully elucidated. Differential diagnosis of melanosis with primary and metastatic malignant melanoma is crucial because of the clinical manifestation and their biological nature differentiation. Here, we have presented a 67-year-old man who was diagnosed with prostatic melanosis with prostatic adenocarcinoma, and differential diagnosis with melanocytic lesions has been discussed.
\end{abstract}

Keywords: Melanosis, prostate, adenocarcinoma

\section{INTRODUCTION}

Prostatic melanosis is a lesion that contains melanocytic granules in both prostatic stroma and epithelium (1). Melanocytic lesions are generally found in the skin, but they can rarely be presented in other parts of the body such as in ovaries, bladder, parotids, esophagus, and vagina (2). The presence of melanin in the prostate gland is a very rare histopathological finding (1). Herein we present a case of a patient who was incidentally diagnosed with prostatic melanosis in radical prostatectomy specimen.

\section{CASE PRESENTATION}

A 67-year-old patient was admitted to urology clinic with lower urinary tract symptoms. His medical history indicated that he had been using alpha blocker for treating these symptoms. Laboratory test results were normal except for high prostate specific antigen level $(10.6 \mathrm{ng} / \mathrm{mL})$. Prostatic multiparametric magnetic resonance imaging (mpMRI) showed no sign of prostatic malignancy, except high prostate volume. Transrectal prostate needle biopsy was performed by urologists and histopathological examination detected prostate adenocarcinoma with 3+4=7 Gleason score. Next, a consent form was obtained from the patient for performing radical prostatectomy. After the operation, the resected tissue was examined at our pathology department.

Microscopic examination revealed the prostate adenocarcinoma with Gleason score $3+4=7$ and brown-black granules in both prostate connective tissue and epithelial cells (Figures 1 and 2). Brown-black granules exhibited positive staining with FontanaMasson stain, which is used for confirming the melanine-containing granules (Figure 3). Immunohistochemistry with HMB 45,
Melan A, and S100 antidote stained negative. As a result of these findings, the patient was diagnosed with prostatic melanosis with prostatic adenocarcinoma. But the patient also consulted with dermatology department for exclusion of primary malignant melanoma diagnosis that might be missing out. Dermatological examination revealed no skin lesions that would suggest primary malignant melanoma.

\section{DISCUSSION}

Melanine pigments are normally found in the skin, hair, retina, and nerve cells (1). However, it is rarely found in the prostatic epithelium and connective tissue (stroma).

Melanocytic lesions of the prostate are classified under the following three types: melanosis, blue nevus, and primary/metastatic malignant melanoma. Of these, two types are described as benign melanocytic proliferation in prostate. The first one, known as blue nevus, contains melanin in the prostatic stromal cells. The second one, known as melanosis, contains melanin pigments in both prostatic stroma and the epithelium (1).

Prostatic melanosis was first reported by Nigogosyan et al. (3) and many of them in the literature have reportedly been incidentally detected. It is also a very rare entity and only 22 cases have been reported since $(2,4)$.

There are two theories related to the pathogenesis of prostatic melanosis. The first one suggests that melanoblasts originate from the neural crest, and then they migrate along with the mesoderm. After the migration of melanoblasts, they turn to melanocytes in the prostatic stroma. The second theory sug-

ORCID IDs of the authors: 0000-0001-5767-5007; i.S. 0000-0002-6013-6378; S.M. 0000-0002-4882-352X.

Corresponding Author: Gizem Teoman, E-mail: dr.gizemcivelek@gmail.com
Received Date: 02.01.2018 Accepted Date: 18.05.2018 (c) Copyright 2019 by University of Health Sciences Gaziosmanpaşa Taksim Training and Research Hospital. Available on-line at www.jarem.org 


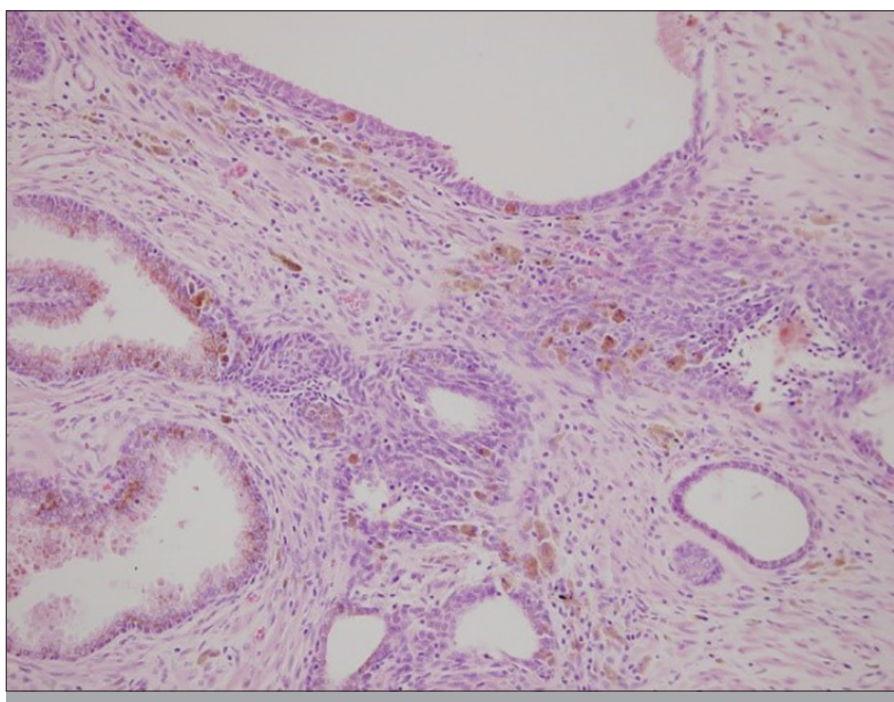

Figure 1. Prostate adenocarcinoma and brown-black granules in both prostate connective tissue and epithelial cells (H\&E x100)

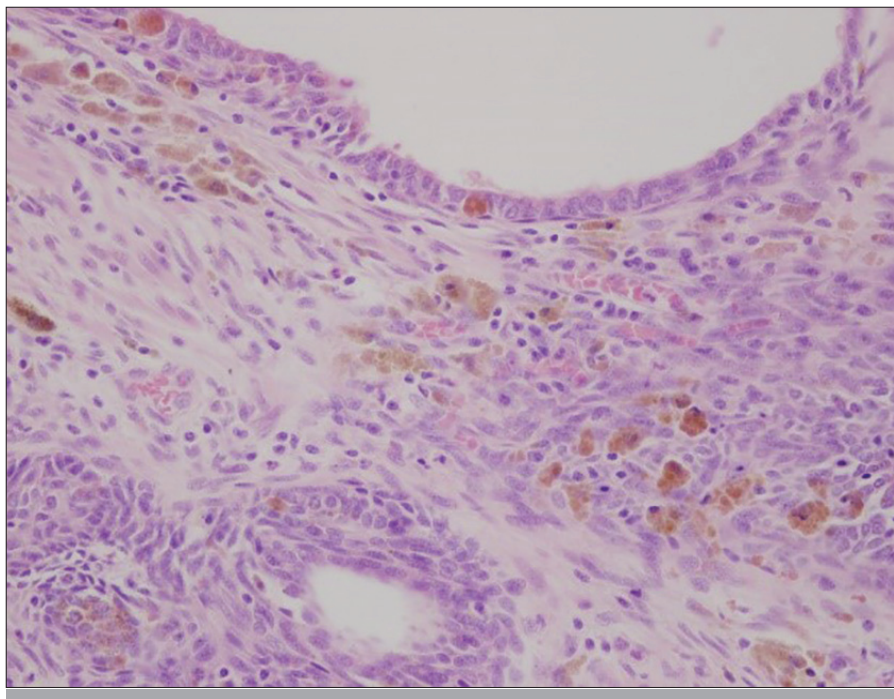

Figure 2. Prostate adenocarcinoma and brown-black granules in both prostate connective tissue and epithelial cells (H\&E x200)

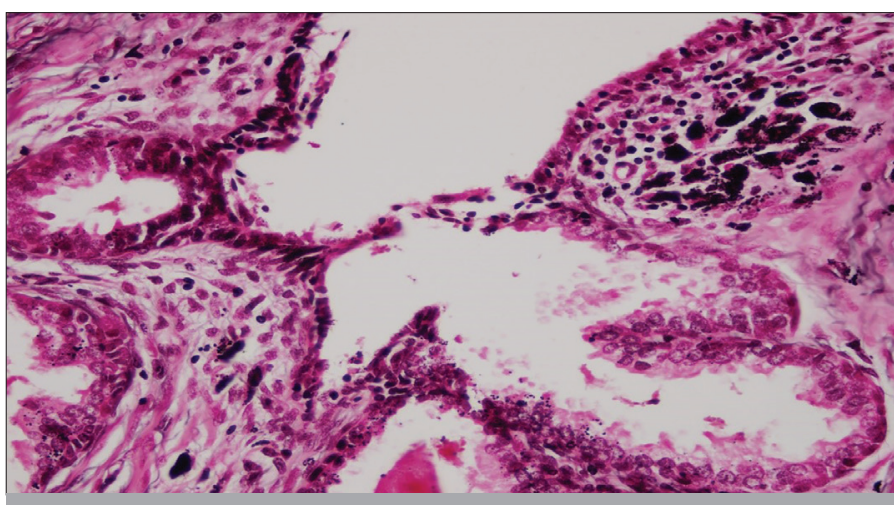

Figure 3. Brown-black melanine granules in positive Fontana-Masson staining $(x 400)$

gests that Schwann cells and endoneural cells are transformed into melanocytes $(5,6)$. Consequently, prostatic epithelial cells have no capacity for melanogenesis except for prostatic stro- mal cells. Therefore, melanin is transferred from stroma to epithelium (7).

Melanine-like granules, such as hemosiderin and lipofuscin, may play an important role in the differential diagnosis. Lipofuscin, a yellow-brown pigment, is found in seminal vesicle and ejaculatory ducts with fine granular structure staining with Luxol fast blue, Sudan black B, and Ehrlich Ziehl-Neelsen. Hemosiderin is a golden pigment with a coarse granular structure accumulating in the macrophages and reacting with Prussian blue. Melanin exhibits positive staining with Masson-Fontana and differentiates from other granules (8-10).

Prostatic melanosis is a benign pathological finding with unknown clinical manifestation. While this entity is accompanied with prostatic adenocarcinoma, there is no evidence for prostatic melanosis might have any role in the prostate cancer development process. Despite the incidental diagnosis of prostatic melanosis, it is crucial to differentiate it from primary and metastatic malignant melanomas. Balaban et al. (11) have reported that $37 \%$ of malignant melanoma cases metastasize to the genitourinary system.

\section{CONCLUSION}

Prostatic melanosis is a very rare entity. In the literature, only 22 cases have been reported since its first description. The association of prostate adenocarcinoma with prostatic melanosis has been reported in three of these 22 cases, except in our case. Since prostatic melanosis is a rare entity and the clinical significance is not fully known, pathologists and urologists should be aware of this entity.

Informed Consent: Written informed consent was obtained from the patient who participated in this study.

Peer-review: Externally peer-reviewed.

Author Contributions: Concept - G.T., I.S.; Design - G.T., I.S.; Supervision - G.T., i.S., S.M.; Resources - G.T., i.S.; Data Collection and/or Processing G.T., I.S.; Analysis and/or Interpretation - G.T., I.S., S.M.; Literature Search - G.T.; Writing Manuscript - G.T., I.S., S.M.; Critical Review - G.T., I.S., S.M

Conflict of Interest: The authors have no conflict of interest to declare.

Financial Disclosure: The authors declared that this study has received no financial support.

\section{REFERENCES}

1. Paner GP, Aron M, Hansel DE, Amin MB. Non-epithelial neoplasms of the prostate. Histopathology 2012; 60: 166-86. [CrossRef]

2. Klock C, Gomes R, João M, Netto G. Prostate melanosis associated with acinar adenocarcinoma. Int J Surg Pathol 2010; 18: 379-80. [CrossRef]

3. Nigogosyan G, De La Pava S, Pickren J, Woodruff MW. Blue nevus of the prostate gland. Cancer 1963; 16: 1097-9. [CrossRef]

4. Gucer H, Bagci P. Prostatic melanosis. Urol Ann 2014; 6: 384. [CrossRef]

5. Reams WM. An experimental study of the development of pigment cells in the coelomic lining of the chick embryo. J Morphol 1956; 99: 513-47. [CrossRef]

6. Nakai T, Rappaport H. A study of the histogenesis of experimental melanotic tumors resembling cellular blue nevi: the evidence in support of their neurogenic origin. Am J Pathol 1963; 43: 175.

7. Çiçek T, Erinanç H, Gönülalan U, Şen E, Öztürk B. Prostatik Melanozis: Olgu sunumu. Cukurova Medical Journal 2014; 39. 
8. Dailey VL, Hameed O. Blue nevus of the prostate. Arch Pathol Lab Med 2011; 135: 799-802.

9. Sanborn SL, MacLennan G, Cooney MM, Zhou M, Ponsky LE. Highgrade transitional cell carcinoma and melanosis of urinary bladder: case report and review of the literature. Urology 2009; 73: 928. [CrossRef]
10. Hameed $O$, Humphrey PA. Pseudoneoplastic mimics of prostate and bladder carcinomas. Arch Pathol Lab Med 2010; 134: 427-43.

11. Balaban M, Selimoglu A, Horuz R, Akca O, Albayrak S. Prostate metastasis of malignant melanoma. Korean J Urol 2013; 54: 486-9. [CrossRef] 